\title{
CUADROS DESCONOCIDOS DE ALONSO LOPEZ DE HERRERA
}

POR

\section{MANUEL TOUSSAINT}

F $\mathrm{N}$ el número 15 de la prestigiosa Revista de Indios, que edita en $\mathrm{Ma}$ drid el "Instituto Fernández de Oviedo", aparece un breve artíctulo de Diego Angulo Iñ́guez, dando cuenta de una Anunciación firmada por Alonso López de Herrera. Cada dia se descubren nuevas pinturas de nuestra época colonial y es natural que de un artista que floreció durante casi toda la primera mitad del siglo $\mathrm{xvIr}$ se desconozcan muchas obras, pues el catálogo de las que existen es bien exiguo. ${ }^{2}$

Felicitábame pues por este hallazgo de Angulo y gozaba con sus atinadas observaciones cuando recordé que en mi archivo de fotografías guardaba una de un cuadro muy semejante. A primera vista parecen iguales, pero una ligera comparación permite establecer que se trata de dos pinturas distintas $y$ aun llegar a conclusiones interesantes.

1 Vkase El Pintor Alonso Lopex de Hetreca, por Manuel Romero de Terreros. Merico, 1934. 
E1 señor Angulo no proporciona ningún dato acerca del origen, paradero, dimensiones, técnica, etc., del cuadro. Supongo que su fotografía, único elemento en que funda su trabajo es bastante buena, pero la reproducción en fotograbado no permite ahondar en detalles, ni aun corroborar sus informaciones pues la firma, por ejemplo, resulta invisible.

Mi fotografía, único elemento en que puedo fundar mis disquisiciones, es una de esas pequeñas fotografías, de seis por ocho centímetros, que $\tan$ en boga estuvieron en el último tercio del siglo xix. No es aislada sino forma parte de una colección de diez y ocho reproducciones semejantes que nos dan a conocer, acaso, algunos de los cuadros que constituían la pinacoteca de algún prócer de esa época. No he logrado identificar tal galería, pero supongo que no será difícil hacerlo. ${ }^{2}$

Procediendo a la comparación de las fotografías, sin abordar aún los problemas de fondo, tenemos: la de Angulo es de proporción más alargada, presenta deterioros en la parte baja, pero, en general, está bien conservado el cuadro; no aparecen rayados sino dos: tuno en la cabeza del Padre Eterno y otro sobre la rueca y cofre; son, empero, tan finos, que parecen pelusas en el negativo que dejaron huellas blancas sobre la positiva. En el borde superior se ve una faja en que los colores han sido menoscabados: me da idea de un bastidor que marca el límite de la tela. Supongo por esto que la fotografía de Angulo reproduce una pintura al óleo sobre tela, de técnica más sobria, menos miniaturista que la que aparece en mi fotografia.

Esta, en efecto, parece reproducir una pintura ejecutada en lámina de cobre, a las cuales era tan afecto López de Herrera. Para justificar este aserto me fundo en las observaciones que siguen. Hay dos partes en que la pintura está desconchada, una en el codo del brazo derecho del ángel y otra arriba de su mano izquierda; puede verse cómo queda al descubierto una faja angostísima del aparejo y el fondo menos oscuro que la pintura: aseguraría que se ve el cobre. No puede ser madera porque ésta conserva siempre parte del aparejo, ni tela porque también lo conserva y si no, se ve la trama. La técnica del cuadro de mi fotografía no es amplia y simple como en el de la de Angulo, sino minuciosa y cuidada hasta en el último detalle. La aureola de la Virgen que allá es una mancha clara que se desvanece en el contorno, aquí está constituida por líneas finas, sin duda de oro, al igual que en las otras pequefias laminas del artista. Los rayados

2 Se decribirá y reproducirá la kerie compleca en el tibro en preparación: Carálogos de colecciones privadas de pinturos en México. 
Son aquí tan claros que caracterizan por sí solos la pintura en cobre. Es pues más que probable que mi fotografía reproduce una pintura pequeña, sobre lámina, con el mismo asunto que la tela de la fotografia de Angulo.

Si procedemos a la comparación de ambos cuadros veremos que hay diferencias capitales. En la tela la Virgen resulta empequeñecida y opacada por el gran grupo de la izquierda en que el ángel se confunde con el Padre Eterno y su corte y aun parece más grande que aquélla.

En la lámina se le da más importancia a la Virgen; el ángel es de menores proporciones y el grupo del Padre Eterno, menos llamativo, no hace contrapeso.

La composición de la tela es francamente defectuosa: no hay equilibrio de masas y se pueden notar errores: la mano derecha del ángel sobre la cabeza de un querubín y la del Padre Eterno en línea recta hacia arriba, en tanto que la otra forma un ángulo recto. La mano derecha de la Virgen forma línea recta con el brazo izquierdo del ángel, lo que ha requerido que el horrible hueco que abajo se formaba se rellenara con el cofre $y$ la rueca.

No sé si será defecto de fotografía, pero la alfombra de tonos claros desvaloriza los primeros términos: la vestidura de la Virgen, el búcaro de flores y aun el reclinatorio y su paño.

En la lámina se concentra el interés en la figura de la Virgen. El ángel es menor y logra el efecto aéreo que quiso darle el artista. EI Padre Eterno, rodeado sólo de querubines, aparece más misterioso aunque no menos bien dibujado. La Paloma del Espíritu Santo que en la tela es de una frivolidad inexplicable aparece resuelta seguramente en la lámina, como en la Transfixión de Santa Teresa.

Ia composición es mucho más equilibrada. El pintor no ha tenido que recurrir detalles desagradables como el cofre y la rueca para llenar el espacio, que resultaba entre la Virgen y el ángel o las vigas abominables que cubren el hueco vacio en el ángulo superior de la derecha en la tela.

La vestidura de la Virgen, su rostro, su cabellera; la cabeza y la anatomía del ángel que en la tela están perdidos, cobran valor y calidad en esta lámina. El lecho, el reclinatorio, el libro, se ven más dignos, más decorosos. No hay cesta ni gato: nuestro pintor es más mistico, menos realista acaso, más manierista, pero más ingenuo también.

¿Cual de estas dos pinturas es anterior? Sin duda la tela. Los defectos de ésta y las correcciones hechas en la lámina lo aseguran. Nos figuramos a este fraile, recluido en su celda, sin preocuparse del mundo, reconstruyendo en pequeñas láminas que no firma, los cuadros que antes le babian 
valido la fama de Divino. Ni su Santo Tomás, ni su Santa Teresa están firmados. Tampoco lo está esta Anunciación. $Y$ son sus obras más puras, más fervorosas, aunque aparezcan, como lo hace notar Angulo con justicia, anacrónicamente retrasadas respecto a la pintura de su época aun en la misma Nueva España en que se dejaba ya sentir la influencia de Sebastián López de Arteaga.

De otras pinturas que puedan atribuirse a este artista queremos hacer mención, en calidad de hipótesis, para su estudio y juicio definitivo. Ellas son, en primer término, la gran tela que existe en el crucero de la Epístola del templo de Santo Domingo en Puebla. Representa la muerte del Santo, rodeado de frailes y ángeles que ayudan al alma a subir al cielo. La altura a que se encuentra colocado el cuadro y los reflejos que causa la luz que de todos lados recibe impiden realizar un estudio eficiente: la entonación de la pintura, algunos de sus modelos y el gran aliento de la obra me han hecho pensar en el pintor dominico.

Deben también compararse con su obra las pinturas al óleo que adornan la parte interior de los soportes en el claustro del convento de Santo Domingo en Oaxaca. Representan santos de la Orden y a alguno de ellos le encuentro bastante parecido con las diferencias naturales de una pintura al óleo sobre piedra que no puede alcanzar la finura de sus otras creaciones, sobre todo la de las láminas.

Del mismo artífice es, sin duda, el Divino Rostro que existe en la Catedral de Puebla: es idéntico a las láminas del mismo tema que se conservan en México, con la peculiaridad que aquél ostenta las tres potencias en forma de cruz de Calatrava detrás de la cabeza de Cristo."

El coleccionista y bibliófilo don Salvador Ugarte posee una tabla con un San Agustin escribiendo, que creo puede atribuirse a López de Herrera; para fundar esta suposición obsérvese cómo hay aquí el mismo concepto acerca de las joyas, los mismos libros con manecillas metálicas, el mismo sillón de Santo Tomás con clavos de cabeza semiesférica, uno grande y cuatro pequeños alrededor y además otro pequeño que forma cruz con los otros; la misma técnica en el paisaje que la que ostenta el de Santa Teresa, y en la barba y cabello de sus Santos Domingos y Divinos Rostros; el mismo escorzo en la mano derecha que en el resto de sus cuadros lo que por sí solo es una firma.

3 La fotografía que publicamos fué enviada por don José Luis Bello, de Puebla, al señor Romero de Terreros. Reproducimos también el Santo Domingo en Sorimo de Churubusco para tener toda la obra del artista publicada y la del enīor Angulo, aunque no de fotografia directa, para comparat con la de Mérico. 

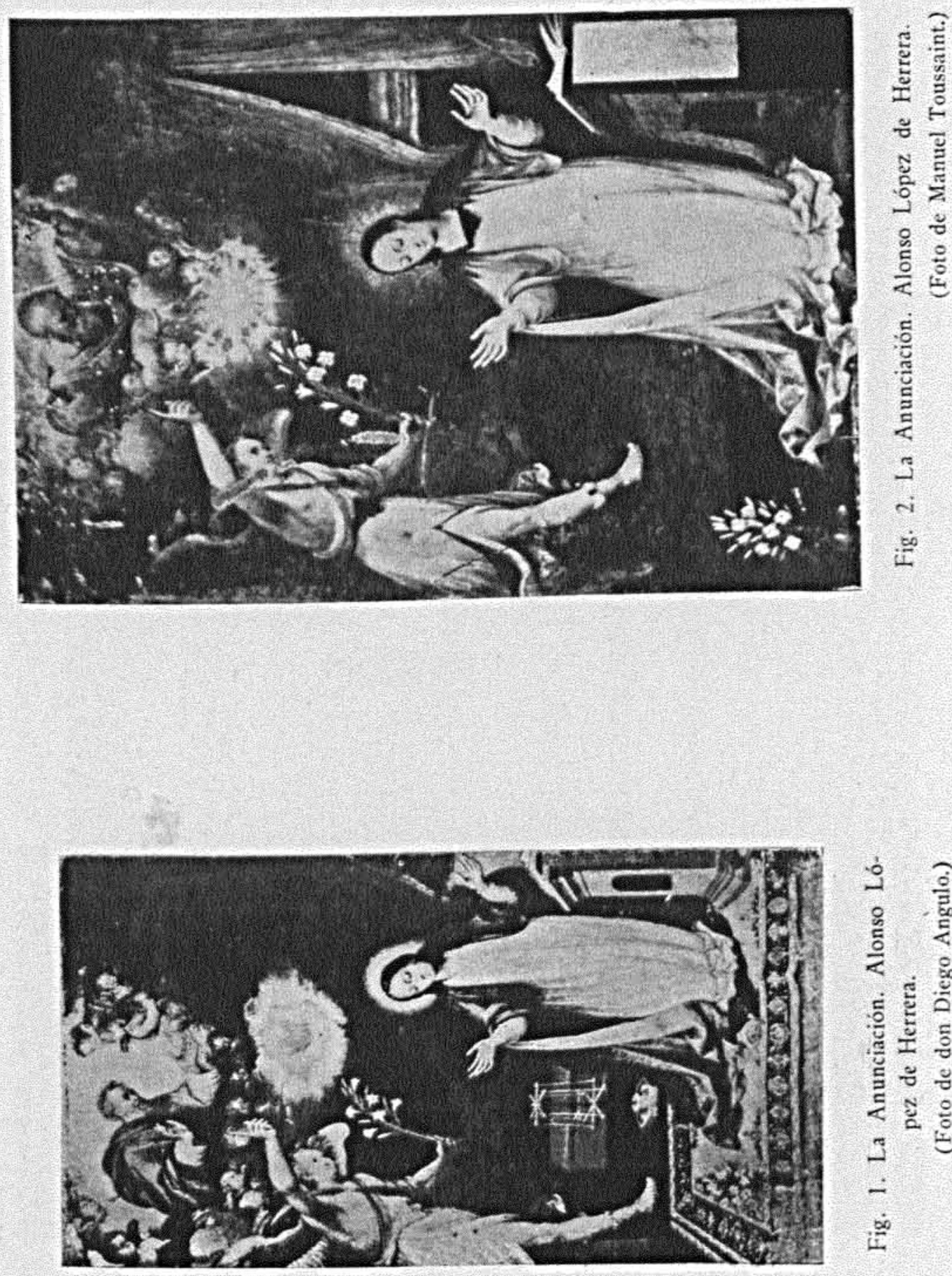

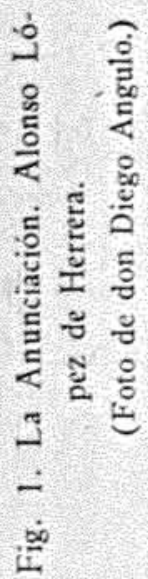


DOI: http://dx.doi.org/10.22201/iie.18703062e.1945.12.388

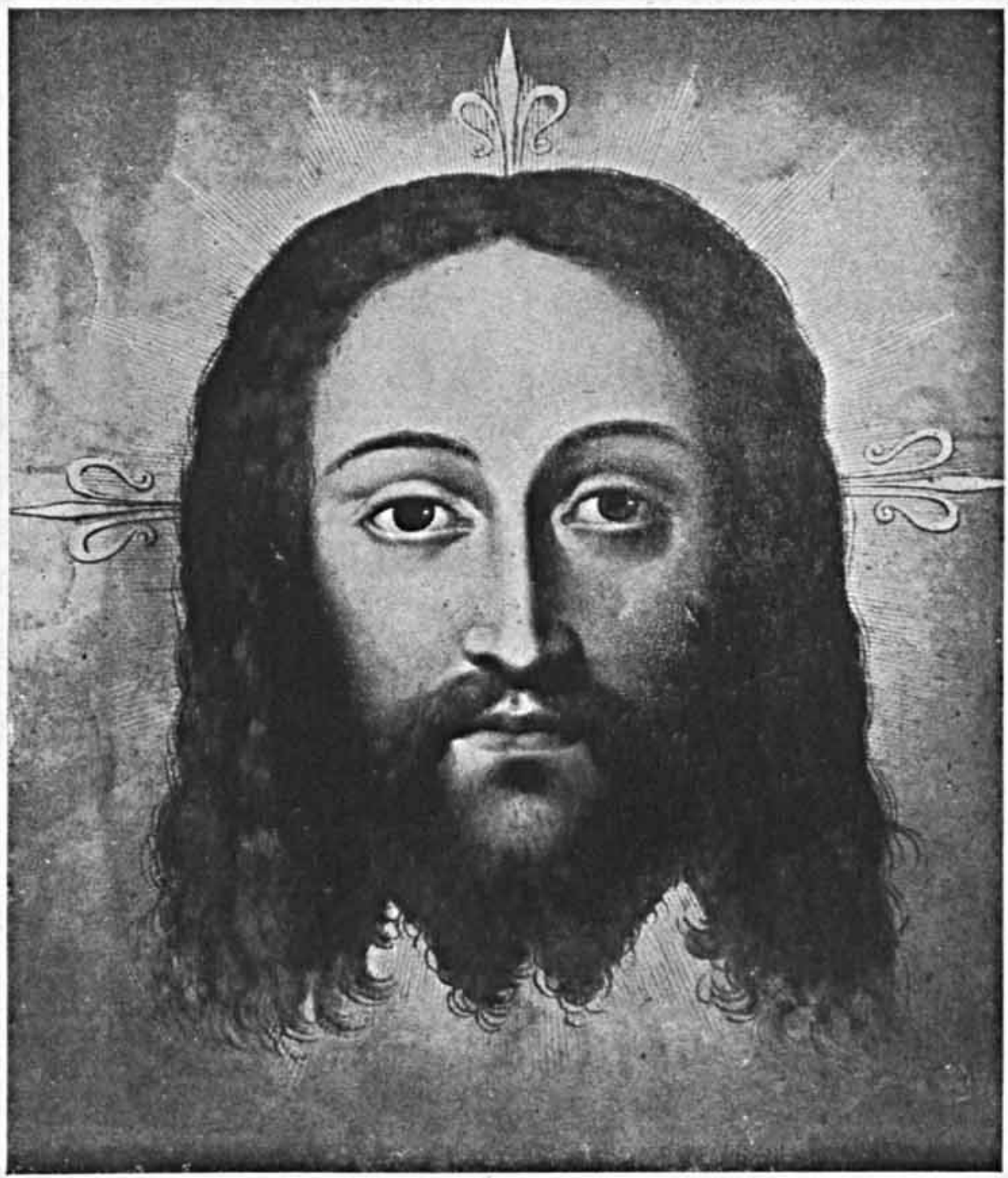

Fig. 3. Divino Rostro. Alonso López de Herrera. Catedral de Puebla. 


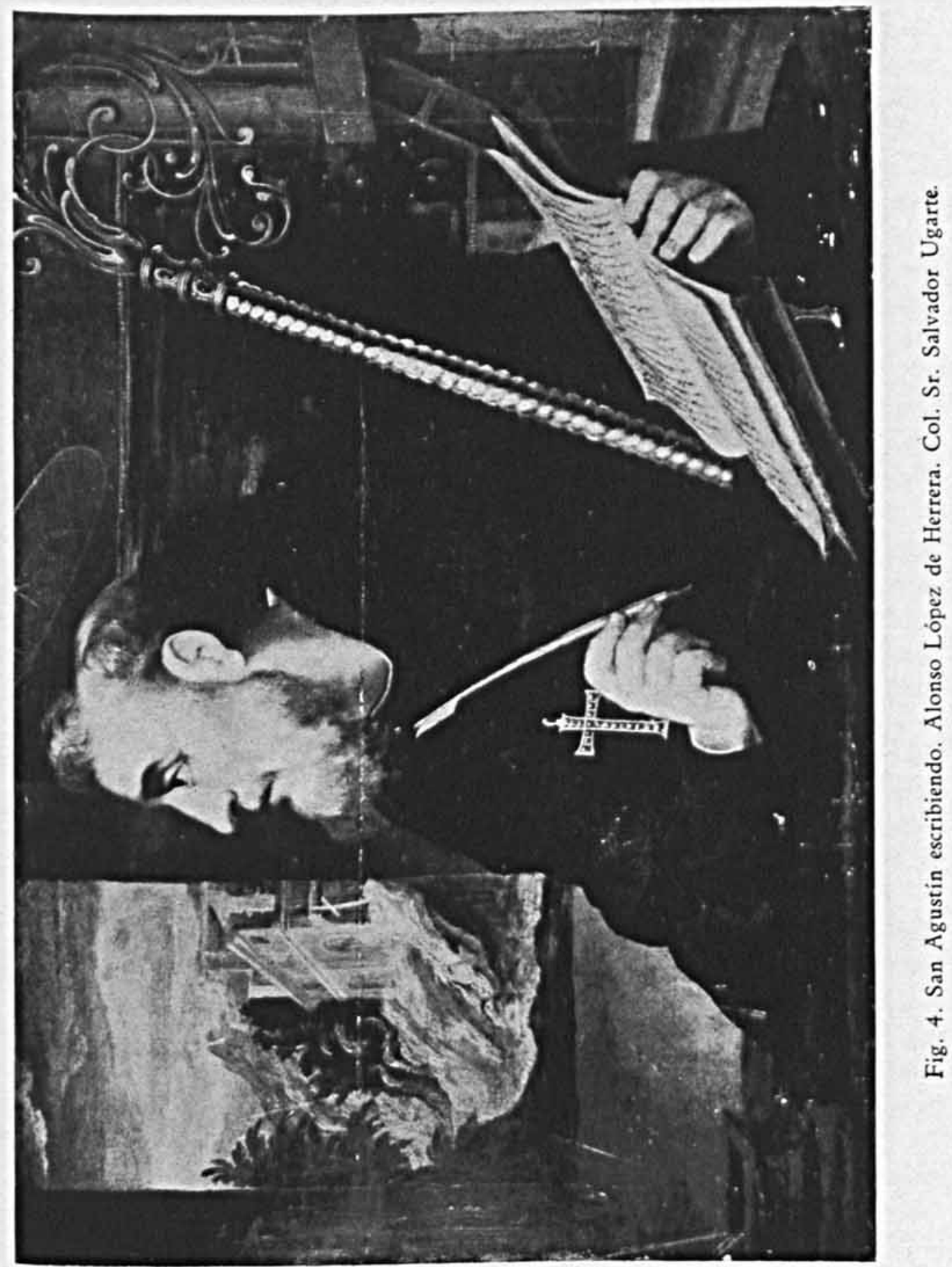




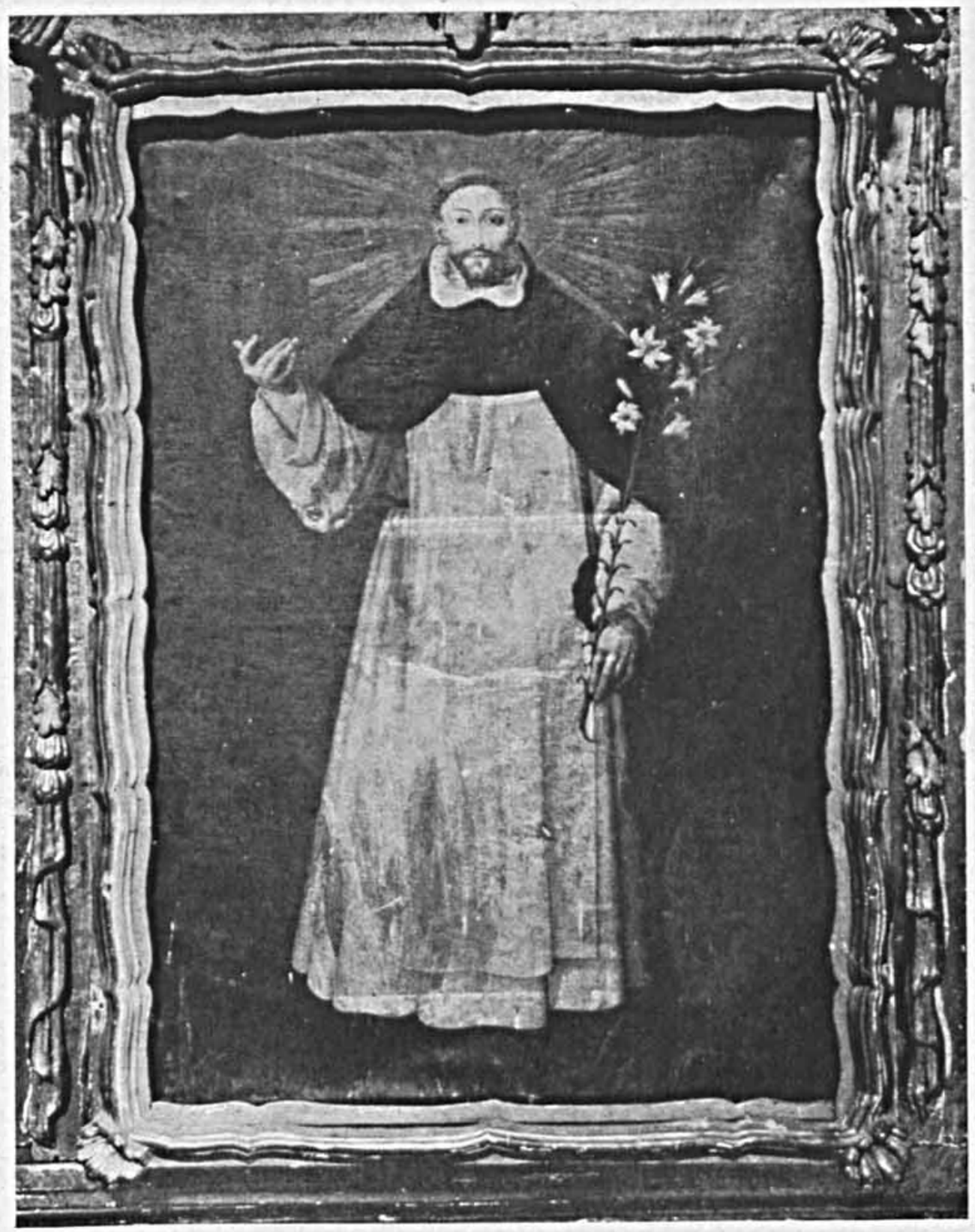

Fig. 5. Santo Domingo en Soriano. Alonso López de Herrera. Iglesia de Churubusco. 
El señor Romero de Terreros supone que un San Jerónimo que existe en el Museo del Alfeñique en Puebla y que fué reproducido en el número 11 de la serie "El Arte en México-Pintura Colonial", es de López de Herrera y no de Miguel Jerónimo Zendejas como en la reproducción se afirma. ${ }^{-}$Realmente, la pintura parece demasiado buena para sed de Zendejas. Además, presenta semejanzas notables con las obras del dominico. Desde luego su minucia y su acabado. Zendejas, que pudiera ser llamado el primer impresionista, porque con todos sus defectos, su obra es de una vitalidad asombrosa, como si supiese atrapar en sus telas un minuto de existencia, parece fuera de lugar aqui donde todo está estudiado y descrito con una paciencia lópez-herreriana. Los libros con sus manecillas de metal, o en pergamino, pintados todos con verdadera fruición, el pliegue de los paños, el escorzo de la cabeza igual que en la Santa de Avila y, sobre todo, las manos. Si López de Herrera nos dejó un mensaje - y ivaya si nos to dejó !- está escrito en el idioma de sus manos. La mano, ese tremendo problema de nuestra pintura colonial, en este fraile dominico es pan comido. Podría hacerse un estudio de las manos de López de Herrera, lleno de observaciones recónditas y misteriosas : él da para todo. A pesar de todas estas afinidades, yo encuentro un reparo fundamental para aceptar la atribución: la audacia. En este San Jerónimo veo una audacia de rojos que está bien lejana de las armonias renacentistas de nuestro divino Herrera. Esta pintura es más moderna y está más empapada en la posterior pintura española que toda la obra del dominico de cuyo anacronismo se queja $\rightarrow$ si bien discretamente- el amigo Angulo. $O$ la reproducción es muy deficiente -cosa que pudiera ser, pues a alguno de estos cuadros no lo reconocería seguramente el pincel que los parió-, o hay que aceptar que el artista tenía ya mucha más experiencia pictórica, no en su propia habilidad, pero si en su repertorio.

Respecto a los datos biográficos del artista también se ha progresado bastante, pues hoy sabernos que nació en la ciudad de México y fué bautizado en el convento de Regina el 24 de febrero de $1579 .{ }^{\circ}$

Para fijar la fecha de su muerte antes de 1654 me fundo en que ese año fué llamado por los frailes del convento de Santo Domingo de México el pintor Nicolás Becerra para que pintase un cuadro que adomaría el

4 Interesante colección publiezda por la "Cervecería Cuaubtémoc" de Monterrey, N. L.

5 Váte su artículo en el "Excelsior" de 6 de marzo de 1936.

6 Dato dexubierto por don Francixo Pétez Salazar $\$$ comunicado por don Manuel Romero de Terreros. 
templo de Santo Domingo, cuadro que, por cierto, provocó uma acusación al Santo Oficio y un proceso porque los dominicos habían dotado a su Patriarca y a otros santos de su Orden con los estigmas y los franciscanos alegaron que eso era privilegio exclusivo suyo $y$ de sus correligionarios. Si López de Herrera viviera aún, d habría ejecutado la obra, ya que fué el pintor oficial de su Orden, digamos así, durante largos años. 